\title{
Investigation of microbiological spoilage and demonstration of the anti- bacterial activity of the major imported fruits within Dhaka Metropolis
}

\author{
Farahnaaz Feroz, Jessica Das Senjuti, Jannatun Tahera, Kamal Kanta Das and Rashed Noor ${ }^{\ddagger}$ \\ Department of Microbiology, Stamford University Bangladesh, 51 Siddeswari Road, Dhaka \\ 1217, Bangladesh
}

Received 17 January 2014/Accepted 22 February 2014

\begin{abstract}
With a previous observation of the in vitro anti-bacterial traits posed by both local and imported fruit alcoholic extracts, present study further endeavored principally to chalk out such properties of the imported fruit blends without alcoholic extraction. Experiments regarding microbiological load demonstrated the prevalence of huge number of total viable bacteria $\left(\sim 10^{7} \mathrm{cfu} / \mathrm{g}\right)$ as was also observed in the earlier research while the fungal load was nominal. Among the pathogenic bacteria, Pseudomonas spp. was found to be more prevalent, closely followed by staphylococcal proliferation. The study of anti-bacterial activity revealed that guava, apple and malta samples possessed strong antibacterial traits while the dragon fruit samples exhibited least activity and the orange samples were found with moderate anti-bacterial activity. On the basis of our earlier results, the findings of the current study thus put forward a comparison among the alcoholic extracts and the crude fruit blends.
\end{abstract}

Key words: Fresh fruits; Microorganisms; Consumer safety; Anti-bacterial activity

Fresh fruits are vital parts of human diet because of their multi-dimensional nutritional benefits along with the traits of being natural antioxidants and antimicrobials (1-6). Conversely, fresh fruits may play role as potential vehicles for the transmission of bacterial, parasitic and viral pathogens to the consumers ultimately leading to the possibility of the onset of food borne diseases (5-10). Earlier studies with fresh fruits and vegetables revealed the huge growth and proliferation of huge bacteria and fungi, especially of Staphylococcus spp., Pseudomonas spp., Listeria monocytogenes, Escherichia coli, Salmonella spp., Vibrio spp. and Aeromonas spp. (5, 6, 9, 11-13). Such microbial contamination in fresh produces has been observed to take place from human, animal and environmental sources during growth, harvesting, transportation and also due to the unhygienic processing and handling of the products $(5,6,8,9)$. Therefore, a complete microbiological profiling of fresh fruits may be useful for the consumer safety. Earlier studies on alcoholic extracts of local and imported fruits and as well as on local fruit blends revealed the strong antimicrobial traits of fruits, further necessitates to study on imported fruits blends to investigate antibacterial activity and also their microbiological profile $(5,6)$.

A common problem regarding the medication

${ }^{\ddagger}$ Corresponding Author. Mailing address: Dr. Rashed Noor, Department of Microbiology, Stamford University Bangladesh, 51 Siddeswari Road, Dhaka, Bangladesh; Email: noor.rashed@yahoo.com. inefficiency due to the rise of antibiotic resistances has recently gone far posing severe public health threat in the developing countries like Bangladesh (14-16). The reason behind such drug resistance have already been well known, especially contributed by the natural transfer of the drug-resistance genes accompanied with the mass consumption of non-prescribed antibiotics (14-17). To combat such problems associated with the antibiotic usage, natural products are being recently explored for their strong anti-bacterial activity without any side effects $(11,18,19)$. Along with proven medicinal plants, fresh fruits are being widely studied now-a-days for medications against pathogenic organisms as they have been reported to possess many of the known phytochemicals capable of performing an array of beneficiary biological functions including anti-bacterial activities (19-23).

In this context, earlier we examined the anti-bacterial activity of the crude blends of the local fruits, and of the alcoholic extracts of both local and imported fruits randomly collected within Dhaka metropolis $(5,6)$. Both the studies revealed a huge number of microorganisms within the samples tested and conversely significant antibacterial traits were also noticed. Such observation further led us to investigate the probability of the existence of the anti-bacterial activity of the crude blends of commonly imported fruits.

\section{MATERIALS AND METHODS}

Sampling and sample processing. Imported samples of five types of fresh fruits including Guava (Psidium guajava), malta (Citrus sinensis), apple (Malus 
domestica), orange (Citrus reticulate) and dragon fruits (Hylocereus polyrhizus) were randomly collected from super shops within the city of Dhaka, Bangladesh $(5,6)$. Samples were collected early in the morning and transported quickly to the laboratory according to the standard method $(5,24)$. Microbiological analyses were carried out according to standard procedures as described earlier $(5,6,8,9,25)$. Briefly $10 \mathrm{~g}$ of each fruit sample was homogenized with $90 \mathrm{ml}$ normal saline and serial dilutions were prepared up to $10^{-6}$.

Quantification of microorganisms. For the enumeration of total viable bacteria (TVB) and fungi, $0.1 \mathrm{ml}$ of each sample from the dilutions $10^{-3}$ and $10^{-5}$ was spread onto the nutrient agar (NA) and Sabouraud's dextrose agar (SDA) plates, respectively $(5,6)$. The NA plates were incubated at $37^{\circ} \mathrm{C}$ for 24 hours and the SDA plates were incubated at $25^{\circ} \mathrm{C}$ for 48 hours. For the estimation of specific bacterial pathogens, $0.1 \mathrm{ml}$ from each of the $10^{-3}$ and $10^{-5}$ dilutions of all samples were spread onto the membrane fecal coliform (MFC) agar and MacConkey agar for the enumeration of total fecal coliform (TFC), and coliforms (i.e., Escherichia coli and Klebsiella spp.), followed by incubation at $44.5{ }^{\circ} \mathrm{C}$ and $37^{\circ} \mathrm{C}$ for fecal coliform and coliforms, respectively for 24 hours. Likewise, Staphylococcus spp. was isolated by spreading $0.1 \mathrm{ml}$ of the diluted samples onto the mannitol salt agar (MSA). The plates were incubated at $37{ }^{\circ} \mathrm{C}$ for 24 hours.

For the isolation and quantification of Salmonella, Shigella, and vibrio spp., the enrichment procedure was applied as described earlier (9). For this purpose, after completing homogenization, $1 \mathrm{ml}$ of samples were transferred into $9 \mathrm{ml}$ of selenite cysteine broth (SCB) and alkaline peptone water (APW) for the enrichment of Salmonella, Shigella, and vibrio spp., consecutively and incubated at $37{ }^{\circ} \mathrm{C}$ for 4-6 hours (9). An aliquot of $0.1 \mathrm{ml}$ of each of the sample from $10^{-3}$ and $10^{-5}$ dilutions were spread onto Salmonella-Shigella (SS) agar and thiosulfate citrate bile salt sucrose (TCBS) agar for the isolation of Salmonella spp. and Shigella spp., and Vibrio spp., consecutively. Followed by incubation at $37{ }^{\circ} \mathrm{C}$, the appearance of typical colonies (if any) was noticed within for 24-48 hours. Finally, a series of biochemical tests were conducted to confirm the identity of all the isolates as described previously $(8,9,25)$.

Determination of anti-bacterial activity. Determination of anti-bacterial activity was performed by using the agar well diffusion method as previously described $(5,6,12,26)$. Culture suspensions of 9 laboratory bacterial strains (Bacillus spp., Pseudomonas spp., Vibrio spp., Escherichia coli, Klebsiella spp., Staphylococcus spp., Listeria spp., Salmonella spp., and Aeromonas spp.) were prepared in normal saline equivalent with the turbidity of the McFarland standard. Each of the test bacterial lawn was made by separately spreading evenly over the separate Muller-Hinton agar (MHA). Wells with volumes of 8 $\mathrm{mm}^{3}$ were made through the MHA $(5,6)$. Each of the crashed fruit blends $(100$ $\mu \mathrm{l})$ was added to the wells along with the disc of gentamicin $10 \mu \mathrm{g}$ as the positive control and an aliquot of $100 \mu \mathrm{l}$ normal saline was used as the negative control (11). After drying the plates were then incubated at $37{ }^{\circ} \mathrm{C}$ for $12-18$ hours. Presence of clear zone (if any) around the samples was analytical for the existence of the anti-bacterial traits of the samples studied.

\section{RESULTS AND DISCUSSION}

Prevalence of microorganisms in the tested samples. Microbiological contamination of fresh produces is well known with its impact on the onset of food borne illness associated with morbidity and mortality $(3,5,6,8,9,11$, 27-29). In cohort to the previous findings, in the current investigation, almost all fruit samples examined were found to be contaminated with colossal number of bacteria and a comparatively moderate load of fungi, mostly observed in the skin portions (Table 1). A massive bacterial load of $\sim 10^{7} \mathrm{cfu} / \mathrm{g}$ was observed along the skin portions of dragon fruit samples, guava and apple samples, while the flesh portion harbored relatively lower number of microorganisms (Table 1). The skin and flesh portions of both orange and malta samples were found to be contaminated with the bacterial load of $10^{5} \mathrm{cfu} / \mathrm{g}$ and $10^{7}$ $\mathrm{cfu} / \mathrm{g}$, respectively. Among the tested samples only the core portions of orange and dragon fruit were free form fungal spoilage; whereas in other samples a nominal proliferation was noticed $\left(\sim 10^{2} \mathrm{cfu} / \mathrm{g}\right)$. Among the bacterial pathogens, Pseudomonas spp. was mostly found to adapt in skin and flesh portions of all fruit samples; whereas Shigella spp. was completely absent (Table 1). Proliferation of Pseudomonas spp. was more prevalent in skin portions $\left(\sim 10^{3} \mathrm{cfu} / \mathrm{g}\right)$, while the bacterial bio-burden in the flesh portions was recorded to be around $10^{2} \mathrm{cfu} / \mathrm{g}$. Besides Pseudomonas spp., the staphylococcal load was scored to be in the rage of $10^{2}-10^{3} \mathrm{cfu} / \mathrm{g}$ and the load of Escherichia coli was marked up to $10^{2} \mathrm{cfu} / \mathrm{g}$. Klebsiella

TABLE 1. Microbial load in the imported fruit samples

\begin{tabular}{|c|c|c|c|c|c|c|c|c|c|c|c|c|}
\hline \multirow[b]{2}{*}{ Sample } & \multirow[b]{2}{*}{ Fractions } & \multicolumn{11}{|c|}{ Microbial colony counts (cfu/g) } \\
\hline & & $\sum_{i}^{\infty}$ & 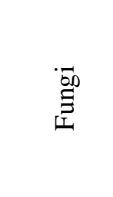 & 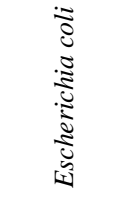 & $\begin{array}{l}\frac{\dot{2}}{2} \\
\frac{0}{0} \\
\frac{\Xi}{0} \\
\frac{0}{0} \\
\frac{a}{2}\end{array}$ & 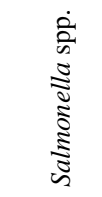 & 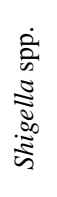 & 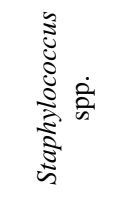 & 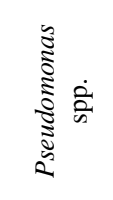 & 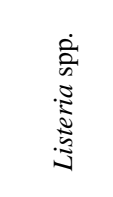 & $\begin{array}{l}\dot{2} \\
\text { के } \\
\stackrel{2}{2} \\
\stackrel{2}{2}\end{array}$ & 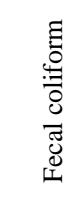 \\
\hline \multirow{2}{*}{ Guava } & Skin & $3.9 \times 10^{7}$ & $2.1 \times 10^{2}$ & $1.8 \times 10^{2}$ & $5.0 \times 10^{2}$ & $2 \times 10^{2}$ & 0 & $1.1 \times 10^{3}$ & $1.5 \times 10^{3}$ & $5.5 \times 10^{1}$ & $1 \times 10^{1}$ & $2 \times 10^{1}$ \\
\hline & Core & $1.2 \times 10^{5}$ & $1.0 \times 10^{2}$ & $5.0 \times 10^{2}$ & 0 & 0 & 0 & 0 & $2 \times 10^{2}$ & $4 \times 10^{2}$ & 0 & 0 \\
\hline \multirow{2}{*}{ Apple } & Skin & $2.3 \times 10^{7}$ & $2.0 \times 10^{2}$ & $4.0 \times 10^{2}$ & $2.0 \times 10^{2}$ & $4.0 \times 10^{1}$ & 0 & $9.0 \times 10^{2}$ & $8.0 \times 10^{2}$ & 0 & $9.0 \times 10^{1}$ & 0 \\
\hline & Core & $2.0 \times 10^{5}$ & $1.5 \times 10^{2}$ & 0 & 0 & 0 & 0 & $5.2 \times 10^{2}$ & $1.5 \times 10^{3}$ & 0 & 0 & 0 \\
\hline \multirow{2}{*}{ Orange } & Skin & $3.4 \times 10^{6}$ & $2.3 \times 10^{2}$ & 0 & 0 & 0 & 0 & $4.1 \times 10^{2}$ & $3.8 \times 10^{3}$ & 0 & 0 & 0 \\
\hline & Core & $1.1 \times 10^{5}$ & 0 & 0 & 0 & 0 & 0 & $4.0 \times 10^{2}$ & $9.0 \times 10^{3}$ & $7.0 \times 10^{2}$ & 0 & 0 \\
\hline \multirow{2}{*}{ Malta } & Skin & $3.8 \times 10^{6}$ & $2.9 \times 10^{2}$ & $9.0 \times 10^{2}$ & 0 & 0 & 0 & $2.8 \times 10^{2}$ & $3.3 \times 10^{2}$ & 0 & 0 & 0 \\
\hline & Core & $2.5 \times 10^{5}$ & $9.0 \times 10^{2}$ & $1.0 \times 10^{1}$ & 0 & 0 & 0 & 0 & $7.5 \times 10^{2}$ & $1.8 \times 10^{2}$ & 0 & 0 \\
\hline \multirow{2}{*}{$\begin{array}{c}\text { Dragon } \\
\text { fruit }\end{array}$} & Skin & $5.6 \times 10^{7}$ & $3.6 \times 10^{2}$ & 0 & 0 & 0 & 0 & $4.2 \times 10^{3}$ & $3.5 \times 10^{3}$ & 0 & 0 & 0 \\
\hline & Core & $2.8 \times 10^{4}$ & 0 & $1.2 \times 10^{1}$ & 0 & 0 & 0 & 0 & $1.8 \times 10^{3}$ & 0 & 0 & 0 \\
\hline
\end{tabular}

$\mathrm{TVB}=$ Total viable bacteria 
Spp., Salmonella Spp. and Vibrio spp. was found only in the skin of guava and apple samples $\left(\sim 10^{2} \mathrm{cfu} / \mathrm{g}\right)$. Fecal coliforms were noticed only in skin of guava samples.

Overall, the proliferation of microorganisms was noticed to be the highest in the guava samples followed by apple samples while dragon fruit samples were found with the least bacterial load, and the orange and malta samples were found to be contaminated to a moderate extent compared to those in the guava and apple samples. The contamination might take place at one or more stages of production to consumer chain and might be due to lack of the standard post-harvest decontamination procedures $(3,5,6,8,9)$.

Anti-bacterial activity of fruit blends against microorganisms. As stated earlier, our previous studies unraveled the fact of strong anti-bacterial activities of the alcoholic extracts of local and imported fruits $(5,6)$. As a continuation of our earlier research, further antibacterial activity of the local fruit blends, without treating with methanol or ethanol, was observed that might facilitate the projection on such activities of the crude and consumable fruit blends. In the present study, guava, apple and malta samples were observed to possess stronger anti-bacterial traits than those of others (Table 2). In case of guava sample, skin portions showed the activity against 7 bacterial strains with zone of inhibition in the range of 7-12.4 $\mathrm{mm}$; while the core/ flesh portions were found to be moderately active against Pseudomonas spp., Vibrio spp. and Salmonella spp. Although the skin portions of apple samples were noticed to exhibit the anti-bacterial activity against 5 test organisms, and the highest activity was scored against Vibrio spp. with an inhibition zone size of 23.85 $\mathrm{mm}$; the flesh portions were found to elicit the activity only against 3 test microorganisms. Neither skin nor the flesh portions of guava samples showed the anti-bacterial activity against E. coli and Aeromonas spp.

The core/ flesh portions of the malta samples studied were found to exhibit the activity against 6 test organisms with the zone size in the range of $8-12 \mathrm{~mm}$; however, the skin portions were found to exert activity only against Pseudomonas spp. and Staphylococcs spp. Both skin and flesh portions of the orange samples showed moderate or even low antibacterial activity against 3 and 4 test organisms, respectively and neither skin nor the flesh portions were noticed to show any activity against Bacillus spp. and Listeria spp. The lowest anti-bacterial activity was exhibited by the skin portions of dragon fruit samples, which was against Staphylococcs spp. (with the zone of inhibition of $10.20 \mathrm{~mm}$ ), whereas the flesh portions showed activity against Bacillus spp. Vibrio spp. (Table 2).

In agreement with the previous studies, our current investigation revealed that Pseudomonas spp. was the most susceptible bacterial strain towards the activity posed by the fruit blends $(2,6,21)$. The susceptibility of the test bacteria could be ordered as following: Pseudomonas spp. against 7 fruit blends ( both skin and core of guava, apple and malta, and only skin of orange); Vibrio (both skin and core of guava and orange, only skin of apple, and only core of dragon fruit) and Staphylococcs spp. (both skin and core of malta, only skin of guava, orange and dragon fruit, and only core of apple) against 6 fruit blends each; Bacillus (only skin of guava and apple, and only core of malta and dragon fruit) and Listeria spp. (both skin and core of apple, only skin of guava, and only core of malta) against 4 fruit blends each; Escherichia coli (only skin of guava and only core of orange and malta), Salmonella spp. (only skin of apple and only core of guava and

TABLE 2. Anti-bacterial activity of the imported fruit blends

\begin{tabular}{|c|c|c|c|c|c|c|c|c|c|c|}
\hline \multirow[b]{2}{*}{ Sample } & \multirow[b]{2}{*}{ Fractions } & \multicolumn{9}{|c|}{ Zone of inhibition $(\mathrm{mm} / 10 \mu \mathrm{l})$ against test organisms } \\
\hline & & 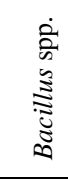 & 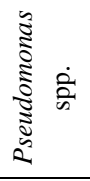 & 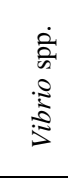 & 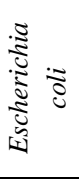 & 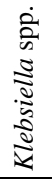 & 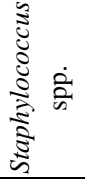 & 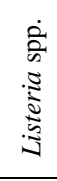 & 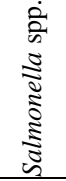 & $\begin{array}{l}\frac{3}{0} \\
\frac{0}{0} \\
\frac{0}{0} \\
\frac{0}{2}\end{array}$ \\
\hline \multirow{2}{*}{ Guava } & Skin & 11 & 12.4 & 10.2 & 9.7 & 0 & 10 & 7.0 & 0 & 9.5 \\
\hline & Core & 0 & 9.7 & 10.8 & 0 & 0 & 0 & 0 & 8.5 & 0 \\
\hline \multirow{2}{*}{ Apple } & Skin & 10 & 12.4 & 23.9 & 0 & 0 & 0 & 8 & 10 & 0 \\
\hline & Core & 0 & 11.9 & 0 & 0 & 0 & 9 & 8.7 & 0 & 0 \\
\hline \multirow{2}{*}{ Orange } & Skin & 0 & 9.5 & 12 & 0 & 0 & 7.3 & 0 & 0 & 0 \\
\hline & Core & 0 & 0 & 11 & 8.4 & 0 & 0 & 0 & 9.8 & 13 \\
\hline \multirow{2}{*}{ Malta } & Skin & 0 & 10.4 & 0 & 0 & 0 & 11 & 0 & 0 & 0 \\
\hline & Core & 10.8 & 8.9 & 0 & 9.2 & 0 & 12.1 & 10 & 0 & 11 \\
\hline \multirow{2}{*}{ Dragon fruit } & Skin & 0 & 0 & 0 & 0 & 0 & 10.2 & 0 & 0 & 0 \\
\hline & Core & 7 & 0 & 9.6 & 0 & 0 & 0 & 0 & 0 & 0 \\
\hline
\end{tabular}


orange) and Aeromonas spp. (only skin of guava and only core of orange and malta) against 3 fruit blends each. Interestingly, although the alcoholic extracts of the imported malta samples were least effective against tested organisms as found previously (6), in the present investigation, the blend of malta flesh/core portion was observed to possess strong anti-bacterial traits against six test organisms. In contrast, the blends of the imported dragon fruit samples were found to possess less anti-bacterial activity than those of their alcoholic extracts as had been noticed earlier (6). In case of the orange samples, both the crude blends and their alcoholic extracts showed the anti-bacterial activity to a similar extent $(5,6)$.

\section{CONCLUSION}

Microbiological profile along with anti-bacterial traits of five selected imported fruit samples presented through this study would be suggestive enough to find out possible way to prevent food borne illness and as well as encourage the consumption of fresh fruits which produces secondary metabolite having anti-bacterial properties. Thus our studies on the microbiological contamination extent within the common fruits along with the anti-bacterial traits of the samples studied would be informative in the light of natural preventive strategies against food borne diseases as well as for the overall consumer safety.

\section{ACKNOWLEDGEMENTS}

Authors thank Stamford University Bangladesh for providing the laboratory facilities and logistic supports.

\section{REFERENCES}

1. Yigit, D., N. Yigit, and A. Mavi. 2009. Antioxidant and antimicrobial activities of bitter and sweet apricot (Prunus armeniaca L.) Kernels. Braz. J. Med. Biol. Res. 42: 346-352.

2. Jelodarian, S., A. H. Ebrahimabadi, and F. J. Kashi. 2013. Evaluation of antimicrobial activity of Malus domestica fruit extract from Kashan area. Avicenna J. Phytomed. 3: 1-6.

3. Quaiyum, S., et al. 2014. Microbiological contamination and anti-bacterial traits of common oral herbal medicinal products within Dhaka Metropolis. European Journal of Medicinal Plants 4 (7): 872-881.

4. Das, S. 2012. Antimicrobial and antioxidant activities of green and ripe fruits of averrhoa carambola linn and Zizyphus mauritiana lam. Asian Journal of pharmaceutical and clinical research 5 (3): 102-105.

5. Senjuti, J. D., et al. 2014. Assessment of microbiological contamination and the in vitro demonstration of the anti-bacterial traits of the commonly available local fruit blend within Dhaka Metropolis. J. Pharmacog. Phytochem. 3 (1): 73-77.

6. Tahera, J., et al. 2014. Demonstration of anti-bacterial activity of commonly available fruit extracts in Dhaka, Bangladesh. Ame. J. Microbiol. Res. 2 (2): 68-73.
7. Chaturvedi, M., V. Kumar, D. Singh, and S. Kumar. 2013. Assessment of microbial load of some common vegetables among two different socioeconomic groups. International Food Research Journal 20 (5): 2927-2931.

8. Feroz, F., J. D. Senjuti, and R. Noor. 2013. Determination of microbial growth and survival in salad vegetables through in vitro challenge test. Int. J. Nutri. Food Sci. 2 (6): 312-319.

9. Rahman, F., and R. Noor. 2012. Prevalence of pathogenic bacteria in common salad vegetables of Dhaka Metropolis. Bangladesh J. Bot. 41 (2): 159-162.

10. Abadias, M., et al. 2008. Microbiological quality of fresh, minimally processed fruit and vegetables, and sprouts from retail establishments. Intl. J. Food Microbiol. 123 (1-2): 121-129.

11. Hoque, M. D. M., et al. 2007. Antibacterial activity of guava (Psidium guajava L.) and neem (Azadirachta A. Juss) extracts against foodborne pathogens and spoilage bacteria. Foodborne pathog. Dis. 4: 481-488.

12. Fadipe, L. A., K. Haruna, I. Mohammed, and G. F. Ibikunle. 2013 Phytochemical and in-vitro antibacterial evaluation of the extracts, portions and sub-portions of the ripe and unripe fruits of Nauclea latifolia. J. Medicinal. Plant Res. 7: 629-636.

13. Fatema, N., M. Acharjee, and R. Noor. 2013. Mcrobiological profiling of imported apples and demonstration of bacterial survival capacity through in vitro challenge test. Ame. J. Microbiol. Res. 1 (4): 98-104.

14. Tenover, F. C. 2006. Mechanisms of antimicrobial resistance in bacteria. American J. Med. 119 (2): 3-10.

15. Mathew, A. G., R. Cissell, and S. Liamthong. 2007. Antibiotic resistance in bacteria associated with food animals: a United States perspective of livestock production. Foodborne Path. Dis. 4 (2): 115-133.

16. Dutta, S., et al. 2013. Study of antimicrobial susceptibility of clinically significant microorganisms isolated from selected areas of Dhaka, Bangladesh. Bang. J. Med. Sci. 12 (1): 34-42.

17. Molton, J. S., et al. 2013. The global spread of healthcare-associated multidrug-resistant bacteria: a perspective from Asia. Clin. Infect. Dis. 56: 1310-1318.

18. Sivapriya, M., D. R. Harsha, S. S. T. Gowda, and L. Srinivas. 2011. Antibacterial activity of different extracts of sundakai (Solanum torvum) fruit coat. Int. J. Biol. Chem. 5: 61-67.

19. Selvamohan, T., V. Ramadas, S. Shibila, and S. Kishore. 2012. Antimicrobial activity of selected medicinal plants against some selected human pathogenic bacteria. Adv. Appl. Sci. Res. 3 (5): 3374-3381.

20. Cragg, G. M., and D. J. Newman. 2013. Natural products: a continuing source of novel drug leads. Biochim. Biophys. Acta. 1830: 3670-3695.

21. Naseer, U., T. Hajera, M. N. Ali, and K. Ponia. 2012. Evaluation of antibacterial activity of five selected fruits on bacterial wound isolates. Int. J. Phar. Bio. Sci. 3 (4): 531-546.

22. Protiva, R. D., et al. 2012. An ethnomedicinal survey conducted among the folk medicinal practitioners of three villages in Kurigram district, Bangladesh. American-Eurasian J. Sustain. Agri. 6: 85-96.

23. Veeresham, C. 2012. Natural products derived from plants as a source of drugs. J. Adv. Pharma. Tech. Res. 3: 200-201.

24. American Public Health Association (APHA). 1998. Standard methods for the examination of water and wastewater. American Public Health Association, Washington, D.C.

25. Cappuccino, J. G., and N. Sherman. 1996. Microbiology - A laboratory manual. The Benjamin/Cummings Publishing Co., Inc., Menlo Park, California.

26. Jagessar, R. C., A. Mars, and G. Gones. 2008. Selective antimicrobial properties of leaf extract against various micro-organisms using disc diffusion and agar well diffusion method. J. Nat. Sci. 6 (2): 24-38.

27. Acharjee, M., F. Rahman, F. Jahan, and R. Noor. 2013. Bacterial proliferation in municipal water supplied in Mirpur locality of Dhaka city, Bangladesh. Clean - Soil, Air, Water 41: 1-9.

28. Munshi, S. K., M. M. Rahman, and R. Noor. 2012. Detection of virulence potential of diarrheagenic escherichia coli isolated from surface water of rivers surrounding Dhaka city. J. Bang. Acad. Sci. 36 (2): 109-121.

29. Butt, A. A., K. E. Aldridge, and C. V. Sanders. 2004. Infections related to the ingestion of seafood part 1: viral and bacterial infections. Lacent Infect. Dis. 4: $201-212$ 